doi: $10.2306 /$ scienceasia1513-1874.2013.39.591

\title{
Evaluation of the antibacterial activities of selected medicinal plants and determination of their phenolic constituents
}

\author{
Fai-Chu Wong $^{\mathrm{a}, \mathrm{b}, *}$, Ann-Li Yong ${ }^{\mathrm{b}}$, Hean-Chooi Ong ${ }^{\mathrm{c}}$, Tsun-Thai Chai ${ }^{\mathrm{a}, \mathrm{b}}$ \\ ${ }^{a}$ Centre for Biodiversity Research, Universiti Tunku Abdul Rahman, 31900 Kampar, Malaysia \\ b Department of Chemical Science, Faculty of Science, Universiti Tunku Abdul Rahman, 31900 Kampar, \\ Malaysia \\ c Institute of Biological Sciences, Faculty of Science, University of Malaya, 50603 Kuala Lumpur, Malaysia \\ *Corresponding author, e-mail: wongfc@utar.edu.my
}

Received 14 Mar 2013

Accepted 28 Jun 2013

\begin{abstract}
The purpose of this investigation was to determine the antibacterial activities of five medicinal plants, against both Gram-positive and Gram-negative bacteria. The levels of phenolic constituents in these medicinal plants were also quantified and compared. Minimum inhibitory concentrations (MIC) were determined colorimetrically using 96-well sterile microtitre plates and treatment with p-iodonitrotetrazolium chloride (violet). Concentrations of selected phenolic constituents were determined using HPLC methods, by comparison to standard plots prepared using catechin, caffeic acid, gallic acid, and quercetin standards. MIC tests indicated that Callicarpa formosana and Melastoma candidum possessed the strongest bacterial inhibitory activities, with MIC values ranging between 12.5 and $37.5 \mathrm{mg} / \mathrm{ml}$ and $0.80-8.3 \mathrm{mg} / \mathrm{ml}$, respectively. M. candidum also demonstrated inhibitory activities against Gram-negative bacteria, with MIC value of $8.3 \mathrm{mg} / \mathrm{ml}$. Quercetin was detected in all medicinal plants tested, with concentrations ranging between 0.25 and $0.47 \mu \mathrm{g}$ per mg of dried sample. Caffeic acid, catechin and gallic acid were detected in only some of the medicinal plants. Our results suggested that $C$. formosana and $M$. candidum could potentially be used for the isolation of potent antibacterial compounds.
\end{abstract}

KEYWORDS: caffeic acid, catechin, gallic acid, herbs, HPLC, minimum inhibitory concentration (MIC), quercetin

\section{INTRODUCTION}

Over the centuries, ethnomedicine in many parts of the world has been using medicinal plants for curing various diseases and promoting of good health. Besides, many modern drugs are based on plant-derived synthetic derivatives ${ }^{1}$. Before the age of penicillin and antibiotic discovery, medicinal plants were frequently used to treat microbial infections. In view of the worldwide recurrence of multidrug-resistant bacterial strains ${ }^{2}$, it becomes an urgency to search for next-generation antimicrobial compounds. Since plants produce diverse polyphenolic compounds as parts of their self-defence mechanism against microbial infection, medicinal plants represent a promising reservoir in the search for novel antimicrobial compounds ${ }^{3}$. Nonetheless, detailed antimicrobial properties of some medicinal plants are not readily available. Frequently, reported antibacterial activities are measured using Kirby-Bauer disk diffusion methods, with no additional information on the exact inhibitory concentration. Moreover, detailed measurements of the individual phenolic or flavonoid constituents are lacking.

In this study, we evaluated the antibacterial properties of five medicinal plants, namely Callicarpa formosana, Clinacanthus nutans, Melastoma candidum, Pereskia bleo and Vernonia amygdalina. C. formosana is a small flowering plant, and other species from the same genus have reportedly been applied in treatments of external bleeding, rheumatism, and fever ${ }^{4}$. C. nutans has reportedly been used in Thailand for treating herpes virus infection ${ }^{5}$. Recently, this plant has received much attention because of its potential application in cancer treatment. M. candidum and $P$. bleo represent two traditional medicinal herbs used in some parts of Asia as diuretic herbal drink ${ }^{6}$. Additionally, V. amygdalina was chosen for this study, as ethnomedicine has been using it in the treatment of bacterial infection ${ }^{7}$.

Here, we tested each of these medicinal plants and compared their minimum inhibition concentrations (MIC), against both Gram-positive, and Gramnegative bacterial strains. Additionally, we used 
Table 1 Minimum inhibitory concentration (MIC, mg/ml) of medicinal plant extracts against Gram-positive and Gramnegative bacterial strains.

\begin{tabular}{lcccc}
\hline Extract & \multicolumn{4}{c}{ Minimum Inhibitory Concentration $(\mathrm{mg} / \mathrm{ml})$} \\
\cline { 2 - 4 } & S. aureus & M. luteus & E. coli & P. aeruginosa \\
\hline C. formosana & $12.5 \pm 0.0$ & $37.5 \pm 12.5$ & $>50$ & $>50$ \\
C. nutans & $>50$ & $>50$ & $>50$ & $>50$ \\
M. candidum & $6.3 \pm 0.0$ & $0.80 \pm 0.0$ & $8.3 \pm 2.1$ & $8.3 \pm 2.1$ \\
P. bleo & $50.0 \pm 0.0$ & $>50$ & $>50$ & $>50$ \\
V. amygdalina & $50.0 \pm 0.0$ & $0.02 \pm 0.00$ & $>50$ & $>50$ \\
Amp & $0.02 \pm 0.00$ & $1.0 \pm 0.2$ & $0.6 \pm 0.0$ \\
\hline
\end{tabular}

Ampicillin (Amp) was included as the positive control. Data are reported as mean \pm SE values $(n=3)$.

reversed phase-high performance liquid chromatography to determine the phytochemical profiles of these medicinal plants. With detailed evaluation of antibacterial activities and measurements of phenolic contents, we wish to contribute to the understanding on these selected medicinal plants and their potential antibacterial applications.

\section{MATERIALS AND METHODS}

\section{Preparation of herbal extracts}

Medicinal plants were collected from April to June of 2012. The plant species were authenticated by Professor Dr Ong Hean Chooi at the Institute of Biological Sciences, University of Malaya, Malaysia. Voucher specimens (Voucher Numbers: MHR-2012-001 to MHR-2012-005) were deposited at Department of Chemical Science, Tunku Abdul Rahman University. The medicinal plants were dried in an oven at $40^{\circ} \mathrm{C}$ for $48 \mathrm{~h}$ or until constant weight was observed. Each dried plant sample was then pulverized. Plant samples were then incubated with distilled water at 1:18 (w/v), followed by heating at $90{ }^{\circ} \mathrm{C}$ for an hour. Supernatant was then filtered using cheesecloth and centrifuged at $14900 \mathrm{~g}$ for $10 \mathrm{~min}$. Clarified medicinal plant extracts were then aliquoted and stored in $-20^{\circ} \mathrm{C}$ until testing.

\section{Determination of minimal inhibitory concentration (MIC)}

MIC assay was performed using the published protocols with modification ${ }^{8,9}$. Briefly, a final bacterial inoculum of $5 \times 10^{5} \mathrm{cfu} / \mathrm{ml}$ is prepared using MuellerHinton broth and aliquoted into a 96-well sterile microtitre plate. Plant extracts were added into the first row of wells, and serial dilutions were performed to achieve final concentrations of 50.0, 25.0, 12.5, 6.3, 3.1, 1.6, 0.8 , and $0.4 \mathrm{mg} / \mathrm{ml}$. The sealed plate was then incubated at $37^{\circ} \mathrm{C}$ for $18-24 \mathrm{~h}$. Next, $20 \mu \mathrm{l}$ of $0.4 \mathrm{mg} / \mathrm{ml}$ of p-iodonitrotetrazolium chloride (INT, Fisher Scientific) was added to each well, followed by $30 \mathrm{~min}$ of incubation at $37^{\circ} \mathrm{C}$. Colour changes to pink were observed. The lowest sample concentration whereby no colour change was observed and recorded as the MIC value. The reported MIC values represented average values of three identical replicate trials. Commercial ampicillin (Sigma-Aldrich) was used as positive control, at the concentrations of 2.50, $1.25,0.63,0.31,0.16,0.08,0.04$, and $0.02 \mathrm{mg} / \mathrm{ml}$. Additionally, sterility control and solvent control were also included in the MIC assays.

\section{HPLC Conditions}

HPLC separation was performed with a Shimadzu HPLC system (Company name: Shimadzu Corporation). Samples were separated on a ThermoScientific ODS Hypersil column $(5 \mu \mathrm{m}, 100 \mathrm{~mm} \times 4.6 \mathrm{~mm})$. Solvent mixtures were as follows: A: distilled water acidified to $\mathrm{pH} 2.74$ with acetic acid, B: acetonitrile ${ }^{10}$. After injecting $20 \mu \mathrm{l}$ of plant extract or phenolic standard, the following elution gradient was applied with a flow rate of $0.8 \mathrm{ml} / \mathrm{min}$ : $0-5 \mathrm{~min}, 5 \% \mathrm{~B}$; 5-22 min, 9\% B; 22-38 min, $11 \%$ B; 38-43 min, $18 \% \mathrm{~B} ; 43-44 \mathrm{~min}, 23 \% \mathrm{~B}$; and $44-54 \mathrm{~min}, 90 \% \mathrm{~B}$. UV-spectra were monitored at $272 \mathrm{~nm}$ for gallic acid (Sigma-Aldrich), $280 \mathrm{~nm}$ for both catechin hydrate (Sigma-Aldrich) and caffeic acid (Sigma-Aldrich), and $370 \mathrm{~nm}$ for quercetin (Acros). The column was eluted at room temperature, and all aqueous solvents for HPLC were filtered through $0.45 \mu \mathrm{m}$ membrane prior to applications (Millipore).

\section{RESULTS}

\section{Minimum inhibitory concentration}

We first tested these medicinal plant extracts against two Gram-positive bacterial strains: Staphylococcus aureus and Micrococcus luteus (Table 1). Based on MIC results, M. candidum exhibited the strongest antibacterial activities, as indicated by its low MIC values $(6.3 \mathrm{mg} / \mathrm{ml}$ against $S$. aureus, and $0.8 \mathrm{mg} / \mathrm{ml}$ 
Table 2 HPLC determination of phenolic constituent concentrations.

\begin{tabular}{|c|c|c|c|c|}
\hline \multirow[t]{2}{*}{ Herb } & \multicolumn{4}{|c|}{ Concentration of phenolic constituents ( $\mu \mathrm{g}$ per mg of dried sample) } \\
\hline & Gallic acid & Quercetin & Caffeic Acid & Catechin \\
\hline C. formosana & $0.04 \pm 0.00$ & $0.43 \pm 0.01$ & ND & $0.66 \pm 0.03$ \\
\hline C. nutans & ND & $0.25 \pm 0.01$ & ND & ND \\
\hline M. candidum & $0.61 \pm 0.03$ & $0.40 \pm 0.01$ & ND & ND \\
\hline P. bleo & ND & $0.52 \pm 0.02$ & ND & ND \\
\hline V. amygdalina & ND & $0.57 \pm 0.03$ & $0.08 \pm 0.01$ & $1.31 \pm 0.08$ \\
\hline
\end{tabular}

'ND' represented 'not detected'. Data are reported as mean \pm SE values $(n=3)$.

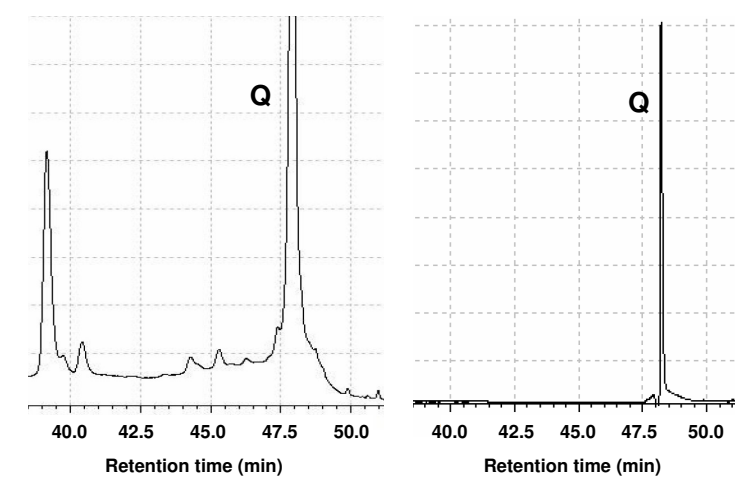

Fig. 1 Representative HPLC chromatograms of V. amygdalina extract (left) and commercial quercetin standard (right), monitored at $370 \mathrm{~nm}$. 'Q' denoted the peak corresponding to quercetin.

against $M$. luteus), followed by $C$. formosana $(12.5 \mathrm{mg} / \mathrm{ml}$ against $S$. aureus, and $37.5 \mathrm{mg} / \mathrm{ml}$ against M. luteus). The observed antibacterial activities of $M$. candidum are 2-fold and 47-fold stronger against $S$. aureus and $M$. luteus, respectively, compared to that of $M$. candidum. Interestingly, the $M$. candidum extract was only 40-fold lower in its anti-M. luteus activities, compared to that of commercial ampicillin.

We next tested these plant extracts against two Gram-negative bacterial strains, namely Escherichia coli and Pseudomonas aeruginosa. With the exception of $M$. candidum, all herbal extracts produced MIC values which are $50 \mathrm{mg} / \mathrm{ml}$ or higher. Notably, $M$. candidum exhibited an MIC value of $8.3 \mathrm{mg} / \mathrm{ml}$ against both $E$. coli and $P$. aeruginosa, which are merely 8-fold and 14-fold weaker than ampicillin.

\section{HPLC analysis}

To quantify the phenolic constituents of these medicinal plants extracts, concentration plots of four standard phenolic compounds (gallic acid, quercetin, caffeic acid and catechin) were prepared (data not shown). HPLC analysis was then performed for each plant extract in triplicate. The concentration of each phenolic constituent was calculated using the respective standard plots and is summarized in Table 2.

Quercetin was detected in all five extracts (Table 2), in the following descending order: V. amygdalina, $P$. bleo $>C$. formosana, $M$. candidum $>C$. nutans. In Fig. 1, HPLC plot for V. amygdalina (top) was compared to that of quercetin standard (bottom), with elution peak at 48.2 min. Gallic acid was detected in $M$. candidum, which is 15 -fold higher than that observed in C. formosana. Catechin was only detected in $V$. amygdalina and $C$. formosana, with the amount observed in $V$. amygdalina 2-fold higher than that of $C$. formosana. Except in $V$. amygdalina, no caffeic acid was detected in other plant extracts.

\section{DISCUSSION}

Recently, in view of the recurrence of the multidrugresistant bacterial strains, much attention has been given to the search of effective antibacterial compounds, including those of plants origin ${ }^{11}$. In our MIC study, C. formosana and $M$. candidum were found to inhibit the Gram-positive bacterium $S$. $a u$ reus, at concentration lower than $50 \mathrm{mg} / \mathrm{ml}$. Among the aforementioned medicinal plants, $M$. candidum exhibited the strongest inhibitory activities, with MIC values as low as 6.3 and $0.8 \mathrm{mg} / \mathrm{ml}$ against $S$. aureus and M. luteus, respectively. Based on our HPLC analysis, moderate level of quercetin, a flavonoid-type flavonol derivative, was detected in $M$. candidum and $C$. formosana. Quercetin and other flavonol derivatives (e.g., kaempferol) have previously been reported to inhibit the growth of $S$. aureus ${ }^{12,13}$. Hence, it is possible that quercetin found in $M$. candidum played a significant role in the observed inhibitory activity against $S$. aureus.

Our HPLC analysis also indicated the presence of catechin, a flavonoid-type flavan-3-ol derivative, in C. formosana. Catechin derivatives, which are abundant in green tea, have previously been indicated 
as the bioactive compounds responsible for bacterial inhibitory activities ${ }^{14}$. Catechin may contribute in a similar manner to the inhibitory activity observed in C. formosana. Additionally, gallic acid, a nonflavonoid hydroxybenzoic acid derivative, was detected in both $C$. formosana and M. candidum. Gallic acid has been identified as the compound responsible for the inhibitory action of Caesalpinia mimosoides against both Gram-negative and Gram-positive bacteria $^{15}$. Hence, the 15 -fold higher gallic acid content in $M$. candidum relative to $C$. formosana, may explain at least in part the greater antibacterial activity in the former. Previous studies have highlighted the importance of synergistic effects among the variety of plant-derived bioactive compounds ${ }^{16-18}$. It is highly possible that the detected quercetin, catechin[E21?] and gallic acid could interact in a synergistic manner to contribute to the bacterial inhibitory activities found in C. formosana and M. candidum.

In general, the protection provided by outer membranes ${ }^{19}$ and efflux pumps ${ }^{20}$ renders the Gramnegative bacteria more resistant towards antibiotics and other antibacterial bioactive compounds, when compared with Gram-positive bacteria. Interestingly, among the five medicinal plants tested, only $M$. candidum exhibited inhibitory activities against Gramnegative bacteria. It was tempting to speculate that antibacterial compounds from $M$. candidum might have impressively high membrane permeabilities and possess physical characteristics which prevented them from being extruded by the bacterial efflux pumps. Both of these factors could potentially enable the accumulation of these antibacterial compounds, inside the bacterial membranes, to an effective concentration which exerted the observed inhibitory activities.

\section{CONCLUSION}

We reported here the MIC values of five medicinal plants, against both Gram-positive and Gramnegative bacteria. The concentrations of selected polyphenolic constituents were also determined using HPLC method. Among the medicinal plants tested, $M$. candidum and C. formosana demonstrated the strongest antibacterial activities, as indicated by their low MIC values. Additionally, M. candidum exhibited inhibitory activities towards Gram-negative bacteria. Further work in this direction could potentially lead to the discovery of powerful antibacterial compounds.

Acknowledgements: This study was supported by the Toray Science Foundation (Japan) and UTAR Research Fund (UTARRF).

\section{REFERENCES}

1. Newman DJ, Cragg GM (2007) Natural products as sources of new drugs over the last 25 years. J Nat Prod 70, 461-77.

2. Jones CH, Hruby DE (1998) New targets for antibiotic development: Biogenesis of surface adherence structures. Drug Discov Today 3, 495-504.

3. Lewis K, Ausubel FM (2006) Prospects for plantderived antibacterials. Nat Biotechnol 24, 1504-7.

4. Jones WP, Kinghorn AD (2008) Biologically active natural products of the genus Callicarpa. Curr Bioactive Comp 4, 15-32.

5. Sangkitporn S, Chaiwat S, Balachandra K, Dechatiwongse Na-Ayudhaya T, Bunjob M, Jayavasu C (1995) Treatment of herpes zoster with Clinacanthus nutans (Bi Phaya Yaw) extract. J Med Assoc Thai 78, 624-7.

6. Malek SNA, Shin SK, Wahab NA, Yaacob H (2009) Cytotoxic components of Pereskia bleo (Kunth) DC (Cactaceae) leaves. Molecules 14, 1713-24.

7. Farombi EO, Owoeye O (2011) Antioxidative and chemopreventive properties of Vernonia amygdalina and Garcinia biflavonoid. Int J Environ Res Publ Health 8, 2533-55.

8. Wiegand I, Hilpert K, Hancock R (2008) Agar and broth dilution methods to determine the minimal inhibitory concentration (MIC) of antimicrobial substances. Nat Protocol 3, 163-75.

9. Andrews JM (2001) Determination of minimum inhibitory concentrations. J Antimicrob Chemother 48(Suppl. S1), 5-16.

10. Kaisoon O, Siriamornpun S, Weerapreeyakul N, Meeso N (2011) Phenolic compounds and antioxidant activities of edible flowers from Thailand. J Funct Foods 3, 88-99.

11. Savoia D (2012) Plant-derived antimicrobial compounds: Alternatives to antibiotics. Future Microbiol 7, 979-90.

12. Liu MH, Otsuka N, Noyori K, Shiota S, Ogawa W, Kuroda T, Hatano T, Tsuchiya T (2009) Synergistic effect of kaempferol glycosides purified from Laurus nobilis and fluoroquinolones on methicillinresistant Staphylococcus aureus. Biol Pharmaceut Bull 32, 489-92.

13. Rodríguez Vaquero MJ, Alberto MR, Manca de Nadra MC (2007) Antibacterial effect of phenolic compounds from different wines. Food Contr 18, 93-101.

14. Daglia M (2012) Polyphenols as antimicrobial agents. Curr Opin Biotechnol 23, 174-81.

15. Chanwitheesuk A, Teerawutgulrag A, Kilburn JD, Rakariyatham N (2007) Antimicrobial gallic acid from Caesalpinia mimosoides Lamk. Food Chem 100, 1044-8.

16. Eloff JN (1998) Which extractant should be used for the screening and isolation of antimicrobial components from plants? J Ethnopharmacol 60, 1-8.

17. Rates SMK (2001) Plants as source of drugs. Toxicon 
39, 603-13.

18. Houghton PJ, Howes MJ, Lee CC, Steventon G (2007) Uses and abuses of in vitro tests in ethnopharmacology: Visualizing an elephant. J Ethnopharmacol 110, 391-400.

19. Delcour AH (2009) Outer membrane permeability and antibiotic resistance. Biochim Biophys Acta Protein Proteomics 1794, 808-16.

20. Nikaido H (1998) Antibiotic resistance caused by gram-negative multidrug efflux pumps. Clin Infect Dis 27, S32-41. 